\author{
"In the modern world, large-scale academic \\ research is one of the few ways of making \\ discoveries that can lead to enhancements \\ in the quality and quantity of interventions \\ that clinicians can deliver."
}

\title{
EDITORIAL
}

\section{Academic research as a way forward}

Academic research is under all kinds of pressures. One example is the Government's Research Assessment Exercise, the mechanism for allocating money to the universities. It demands such minutely-detailed accountability that few professors dare to try really innovative science; they fear the experiments will not work perfectly first time, and their institutions will be punished with budget cuts.

The pressures are no less severe in dental fields than in other disciplines. As Professor Jonathan Sandy recently highlighted in his Northcroft Lecture to the British Orthodontic Society, the number of academics working in orthodontics in the UK has fallen by more than a third in the last two decades.

Although these pressures may seem inexplicable to practising scientists, it is not difficult to see how they arose. When a patient finds that no local NHS dentist is accepting new patients, or when a Primary Care Trust is limiting the number of contacts it provides, it seems difficult to justify spending well over a billion pounds a year of taxpayers' money on academic medical research. Even dental surgeons, with their scientific training, hardly have time to ruminate on the benefits of cell biology experiments when their appointment books are full, staff appraisals need to be carried out and a course of continuing professional development completed.

A $B D J$ editorial recently asked the question, "What on earth do dental researchers do all day that is of relevance to the real world?" (BDJ 2006; 200: 649). The truth is that in the modern world, large-scale academic research is one of the few ways of making discoveries that can lead to enhancements in the quality and quantity of interventions that clinicians can deliver.

The Chancellor of the Exchequer, Gordon Brown, recently announced the merger of the Medical Research Council and the National Health Service research budgets into a single fund. It will still be held in two separate pots, but each will become much more aware of what the other is doing.

These are not in fact the only funds relevant to dental science - research on bacterial communities in human mouths might be funded by the Natural Environment Research Council, while a study of how to make more people clean their teeth properly would fall to the Economic and Social Research Council.

But by integrating the two main players, the Government hopes to bring more clarity to the process of delivering medical benefits through science. It wants to see a more seamless process from the blue-skies discovery that may impress academic colleagues to the clinical trial that demonstrates how effective a new treatment could be.
That is an ambitious aim, and if the whole exercise is to make a difference, a number of players will need to work hard. Part of the process is underway, as academic researchers are increasingly incentivised to think at the earliest possible stage about the potential applications of their work.

Also important is a realisation that turning new knowledge into new treatments is not a one-way street: the best medical research is informed by the real experience of clinical practitioners. So the more clinicians get involved, the more likely we are to see success. This may require a change of culture among some practising dentists, doctors and surgeons, many of whom do not always think of themselves as scientists, but who are in fact in the frontline of delivering science to the public.

Most of all, the Government must be alive to the fact that hard-pressed public servants whether in hospitals, surgeries or universities, will always do their best within limited resources, but that the ways they are measured and managed will drive their behaviour in major ways. Funding and incentive structures must promote desirable behaviours.

Resources might be made available to allow practising clinicians to take sabbaticals in research laboratories. And if academics are expected to make big new discoveries that might open up significant new medical opportunities, simultaneously putting them in the running for a Nobel Prize, everyone must accept that for each major success there will be many less impressive results and even a few dead ends.

To achieve these things effectively, the scientific community needs to engage in alliances with its representative and membership bodies such as the Campaign for Science \& Engineering and more specialised bodies such as the British Dental Association and the Academy of Medical Sciences.

The potential for British academic medicine is enormous, and the Government's renewed interest is a big opportunity if each of the different constituencies involved chooses to engage, and lobbies politicians to optimise the final outcome.

\author{
Dr Peter Cotgreave \\ Director \\ Campaign for Science $\mathbb{A}$ Engineering \\ peter@sciencecampaign.org.uk \\ www.sciencecampaign.org.uk
}

